\title{
A mini-review of ambulatory teaching techniques oriented for endocrinologists
}

\section{Mini review}

The tradition of bedside education dates back to the early days of medicine. The first two principles of the Hippocratic method are: "Observe all" and "Study the patient rather than the disease". ${ }^{1}$ The famous Dutch physician Franciscus Sylvius was one of the first to record his thoughts regarding teaching on rounds: "My method (is to) lead my students by hand to the practice of medicine, taking them every day to see patients in the public hospital, that they may hear the patient's symptoms and see their physical findings". ${ }^{2}$ Sir William Osler, who co-founded Johns Hopkins Medical School with Harvey Cushing and created the institution's clinical clerkship for medical students and residency program, insisted that trainees learn from seeing and talking to patients rather than from didactic lectures. He wrote that "He who studies medicine without books sails an uncharted sea, but he who studies medicine without patients does not go to sea at all. ${ }^{3}$ These lessons stress the development of "practical knowledge," which is essential for creating life-long learners and excellent physicians. These principles are not acquired through self-study or in the lecture hall, but rather learned in the care of patients under the tutelage of an experienced mentor.

Despite the importance of bedside teaching, time spent teaching at the bedside has declined in recent years from $75 \%$ prior to the 1960 s to much less than $20 \%$ today. ${ }^{4-7}$ This profound drop in bedside teaching correlated with the dramatic changes in health care in the 1980 s-2000s, when a great deal of patient care shifted from the inpatient to the outpatient setting. ${ }^{8}$ Organizations such as Accreditation Council for Graduate Medical Education recognized it was time to move trainees from the inpatient into the outpatient setting, where they can see the majority of medical problems, particularly those related to endocrinology. Subsequently, medical schools, residency programs, and fellowship programs drastically shifted a great deal of learner time from traditional hospital inpatient environments to ambulatory sites, ensuring that learners would have opportunities to encounter patients and experience "practical learning". ${ }^{8}$

Paralleling this paradigm shift have been efforts to provide a greater emphasis on learner-centered teaching, where the emphasis is on andragogy, as contrasted with the classic pedagogical teaching methods. In andragogy, the learner is viewed as an internally motivated individual who draws on life experiences to direct his or her own learning. Subsequently, the emphasis of teaching is on helping stimulate the curiosity of the learner and increase long-lasting knowledge while still taking care of the patient.

However, with increased demands on all endocrinologists, from meeting patient care and research requirements to more time devoted to tasks such as writing notes and submitting prior authorizations, it is incredibly difficult to incorporate successful medical education into a busy clinic session. Two teaching techniques ("Five Microskills"., 9,10 and "SNAPPS"). ${ }^{11}$ have been developed that enhance and improve the efficiency of clinical education, and that can be readily applied to ambulatory endocrine education.
Volume 5 Issue 3 - 2017

\author{
David A Cohen,' Joseph Truglio² \\ 'Beth Israel Deaconess Medical Center, Harvard Medical School, \\ USA \\ ${ }^{2}$ The Mount Sinai Hospital, Icahn School of Medicine at Mount \\ Sinai, USA
}

Correspondence: David A Cohen, Beth Israel Deaconess Medical Center, Harvard Medical School, 330 Brookline Avenue, Boston, MA, 022I5, USA, Tel 617-667-9344,

Email dcohen3@bidmc.harvard.edu

Received: July 23, 2017 | Published: August 8, 2017

\section{Microskills}

\section{Get a commitment (to diagnosis, evaluation, or treatment)}

When the learner has finished presenting the case (such as a patient presenting with an adrenal incidentaloma discovered on FDG/PET), they often stop. Instead of interjecting your thoughts (which stops the learners thought processes), ask the learner what he/she thinks about the case. This encourages the learner to process the information gathered (rather than just report it), activates and engages the learner, conveys that you think the learner's opinion matters, and increases learner autonomy and ownership over the patient, leading to an increased investment in the patient's care.

\section{Probe for supporting evidence}

When you ask questions such as "What factors did you consider in making the decision to test for pheochromocytoma? "or" Were there potential diseases related to the adrenal gland that you considered and discarded?" the learner reflects upon the mental processes used to arrive at the commitment. At the same time, you find out more about what the learner knows about the patient as well as his/her fund of knowledge. Called "diagnosing the learner," this step allows your subsequent teaching to target his/her level of knowledge and analytic processes

\section{Teach general principles}

Once you have a good idea of the learner's baseline knowledge, you are able to provide 1-2brief relevant and teaching points (such as analyzing the alternative methods used to test for Cushing's Syndrome) which will help fill the learner's knowledge gaps and improve patient care. It is also an opportunity to role model higher order critical thinking techniques.

\section{Reinforce what was done right}

By providing the learner with specific positive behaviors (rather 
than saying "good job"), you are not only reinforcing correct actions that will make them become more firmly established, you are building rapport and trust, improving future interactions and teaching situations.

\section{Correct any mistakes}

Point out to the learner that you are giving feedback, but make sure it is given at an appropriate time, being sensitive to how you present your thoughts. The comments should be specific and focused on observed gaps in medical knowledge or errors in clinical reasoning, rather than discussing personality traits, which may offend the learner and prevent the correction from being a learning opportunity.

\section{SNAPPS}

\section{Summarize}

Using a higher level of abstraction, the learner integrates the entire history and physical (such as about a patient with newly diagnosed diabetes mellitus) in a presentation lasting fewer than three minutes. This integration of information prepares them to think critically about the case and begin planning the care on his/her own.

\section{Narrow the differential diagnosis}

The learner provides a short list of options, which may involve diagnosis (type 1, type 2, MODY, or LADA), treatment (diet, oral medications, or insulin), or preventative health strategies (screening for retinopathy, nephropathy, or foot ulcers). This step requires a commitment from the learner, motivating them to provide patient care on his/her own.

\section{Analyze the differential by comparing and contrasting}

On his/her own, the learner verbalizes the thought processes that led to the differential diagnosis ("likely LADA given the lean elderly patient with a lack of personal or family evidence of insulin resistance and the positive GAD65 antibodies"), helping him/her to gain a better understanding of the patient while you gain a better understanding of the learner's level of knowledge.

\section{Probe the preceptor}

This is the opportunity for the learner to explore the limits of his/her knowledge by asking you a question ("Is there a role for immunomodulation to prevent progression of beta cell autoimmune destruction") to assist with the care of the patient or to round out his/ her knowledge base. It is also the time for you to get to educate, not by giving a lengthy didactic, but a concise and relevant teaching point. This interaction reinforces you as a knowledge resource, rather than as a lecturer.

\section{Plan management}

The learner takes the next steps in the patient's care, by committing to a diagnostic or therapeutic plan ("patient requires treatment with basal and bolus insulin").

\section{Select a case-related learning issue}

Finally, with your assistance, he/she chooses an area of uncertainty to follow-up on outside of the clinic session ("is there evidence behind use of insulin pump therapy in patients over the age of 75"). This learning shouldn't take the learner more than 10-15 minutes, but it reinforces the importance of life-long learning. Following up on this learning (either over email in the ensuring days or at the next session) is essential to role model positive behavior and to show him/her the importance of his/her.

Five Microskills and SNAPPS are highly effective for improving efficiency in ambulatory endocrine education.

Both techniques permit the preceptor to diagnose the level of the learner's understanding, allowing for more focused and concise teaching. However, they have very different benefits, and neither is perfect in every setting. During the interactive discussion in Five Microskills, there is an explicit opportunity for the preceptor to provide feedback to the learner, an essential piece to improve future behavior and patient care. Alternatively, while SNAPPS does not provide feedback, it does force the learner to think critically and to learn more about the case outside of the interaction, an essential component of lifelong learning. However, because SNAPPS is driven by the learner, it requires that the learner understand how to use the technique and have practice; therefore, this technique may be preferable in more advanced learners and among those who have a longitudinal experience. Choice of the appropriate technique for the learner and the clinical context can help the preceptor navigate the dual-responsibilities of teaching and patient care for endocrinologists.

\section{Acknowledgments}

None.

\section{Conflicts of interest}

The authors declare that there are no conflicts of interest.

\section{Funding}

None.

\section{References}

1. http://www.healthguidance.org/entry/6338/1/Hippocrates

2. Tubbs RS, Linganna S, Loukas M. Franciscus Sylvius (1614-1672) a historical review. Childs Nerv Syst. 2007;23(1):1-2.

3. Michael Bliss. William Osler: A life in medicine. New York, USA: Oxford University Press; 1999. p. 581.

4. Reichsman F, Browning FE, Hinshaw JR. Observations of undergraduate clinical teaching in action. J Med Educ. 1964;39:147-163.

5. Nair BR, Coughlan JL, Hensley MJ. Student and patient perspectives on bedside teaching. Med Ed.1997;31(5):341-346.

6. Crumlish CM, Yialamas MA, McMahon GT. Quantification of bedside teaching by an academic hospitalist group. $J$ Hosp Med. 2009;4(5):304307.

7. LaCombe MA. On bedside teaching. Ann Intern Med. 1997;126(3):217220

8. Olson LG, Hill SR, Newby DA. Barriers to student access to patients in a group of teaching hospitals. Med J Aust. 2005;183(9):461-463.

9. Neher JO, Gordon KC, Meyer B, et al. A five-step microskills model of clinical teaching. J Am Board Fam Pract. 1992;5(4):419-424.

10. Parrot S, Dobbie A, Chumley H, et al. Evidence-based office teaching - the five-step microskills model of clinical teaching. Fam Med. 2006;38(3):164-167.

11. Wolpaw TM, Wolpaw DR, Papp KK. SNAPPS: a learner-centered model for outpatient education. Acad Med. 2003;78(9):893-898. 